\title{
Aspects of cognitive activity in schizophrenia
}

\author{
R. TISSOT ${ }^{1}$ AND Y. BURNAND
}

\author{
From the Psychiatric Clinic of the University of Geneva, Bel-Air, Switzerland
}

\begin{abstract}
SYNOPSIS The application of Piaget's genetic psychology tests to schizophrenic patients yielded the following findings. The intelligence quotient of schizophrenics, although within the normal range, is slightly lower than that of a control population of similar age. This is due not to a loss of the operations of the intellect, but to a difficulty experienced by the patients in actualizing the operations. The difficulty is seen particularly in operations dealing with specific objects which require a constant maintenance of the equilibrium between assimilation and accommodation. The thought processes of hebephrenic patients oscillate between excessive assimilation, resulting in a distortion of observable data, and excessive accommodation which by adhering to the observable data distorts the reasoning process. The thought processes of paranoid schizophrenics are dominated by excessive assimilation. This predominance explains their tendency to distort observable data and their difficulty in the generalization of reasoning; it also has an impact on the assimilation/accommodation equilibrium of their logical operations, leading to $(a)$ difficulties in delimiting reflecting abstractions, and therefore the comprehension and extension of concepts, and $(b)$ loss of proof based on logico-mathematical reasoning and, as a result, a propensity to resort to magical thinking and subjective explanations.
\end{abstract}

\section{INTRODUCTION}

The objective of this paper is not to 'measure' once again the performance of schizophrenic patients, but rather to attempt to grasp the structure of their reasoning and its integration with reality. Clinical experience does not suggest that the reasoning structure of schizophrenics is impaired. If, however, these patients have preserved the capacities which they learned before the onset of their illness, why are they no longer able to utilize them as normals do? Why are they unable to integrate the operations with reality?

All adaptive biological activity results from or involves an equilibrium between the assimilation of the external world and the accommodation to it. Mastery of the external world results from achievement of this equilibrium. The relative inefficiency and inadequacy of operations in schizophrenic patients may be caused by a disruption of this balance. If such is the case, schizophrenic cognitive activity may oscillate between complete assimilation, such as may be seen in children's symbolic play and in dreams, and complete accommodation, such as may be seen in pure

1 Address for correspondence: Professor R. Tissot, Psychiatric Clinic of the University of Geneva, Bel-Air, CH-1225 Chêne-Bourg, Switzerland.

0033-2917/80/2828-5690 \$01.00 (C) 1980 Cambridge University Press imitation, which in its extreme forms can become devoid of all meaning, as in stereotypies.

It may be possible to verify this hypothesis by means of the genetic psychology tests which have been developed by Piaget and his co-workers. According to Piaget (1950), the equilibrium between assimilation and accommodation shifts according to the type of cognitive activity involved. In logico-mathematical reasoning, accommodation is achieved by its initial genesis through the reciprocal assimilation of action schemata. Thenceforward, its application to deductive reasoning only requires the assimilation of abstract concepts, without any accommodation. At the other extreme, in reproducing a static image of the world one reduces assimilation to its simplest form because, ultimately, this activity does not require any global assimilatory schema. In contrast, the equilibrium must be maintained and checked when the operation involves spatial representation, especially the representation of a movement (aporia of Zénon d'Elée), or when it involves logico-experimental reasoning (the assimilation of real objects to the structures of reasoning, not arbitrary 'objects' in the general sense).

If the assimilation/accommodation equilibrium of schizophrenics is impaired, one would 
expect them to perform better on tests of abstract logico-mathematical reasoning and on tests of static spatial representation than on tests of logico-experimental reasoning and spatial transformations.

We summarize here 2 experiments carried out to test this hypothesis.

\section{METHOD}

The genetic psychology tests developed by Piaget (Piaget \& Inhelder, 1941, 1948, 1951, 1959, 1966; Piaget et al. 1972, 1974a,b) in the areas of logico-mathematical reasoning, logico-experimental reasoning, spatial representation and mental imagery were utilized. A detailed description of these tests can be found in the original French publications. A population of 36 patients (21 hebephrenic schizophrenics and 15 paranoid schizophrenics) and 11 age-matched controls were studied.

\section{RESULTS}

\section{Quantitative aspects}

The intelligence quotients (WAIS) of the patients were slightly lower than those of the controls,

Table 1. Test results and their significance: totals of functional special features in reasoning, by subject group

\begin{tabular}{|c|c|c|c|}
\hline Group & $\begin{array}{c}\text { Functional } \\
\text { special } \\
\text { features } \\
\text { related to } \\
\text { assimilatory } \\
\text { pre-dominance } \\
(1-6)\end{array}$ & $\begin{array}{c}\text { Functional } \\
\text { special } \\
\text { features } \\
\text { related to } \\
\text { accommodatory } \\
\text { pre-dominance } \\
\text { (12) }\end{array}$ & $\begin{array}{l}\text { Functional } \\
\text { special features } \\
\text { not directly } \\
\text { related to the } \\
\text { assimilation } \\
\text { accommodation } \\
\text { equilibrium } \\
(7-11)\end{array}$ \\
\hline $\begin{array}{l}\text { Normal } \\
\text { controls } \\
\text { (11) }\end{array}$ & 28 & 3 & 10 \\
\hline $\begin{array}{l}\text { Paranoid } \\
\text { schizo- } \\
\text { phrenics } \\
\text { (15) }\end{array}$ & 308 & 10 & 85 \\
\hline $\begin{array}{l}\text { Hebephreni } \\
\text { schizo- } \\
\text { phrenics } \\
\text { (21) }\end{array}$ & 116 & 34 & 14 \\
\hline \multicolumn{4}{|c|}{$\begin{array}{cl}\chi^{2} \text { test: } & \\
\mathrm{T} \times \mathrm{P} \times \mathrm{H}, & P<0.005 \\
\mathrm{~T} \times \mathrm{P}, & P<0.05 \\
\mathrm{~T} \times \mathrm{H}, & P<0.05 \\
\mathrm{P} \times \mathrm{H}, & P<0.005\end{array}$} \\
\hline
\end{tabular}

but were well within the normal range. The operational level of the patients, as measured by Piaget's genetic tests, did not differ significantly from that of the controls. The success rates on the tests of conservation of physical quantities were $100 \pm 0.01 \%$ for the controls, $93.79 \pm 9.45 \%$ for the paranoid schizophrenics and $100 \pm 0.01 \%$ for the hebephrenics.

By contrast, the results for the patient population were not homogeneous in terms of the kinds of operations performed. Those operations which were best conserved (far left) and those least well conserved (far right) for the control and patient groups are indicated below:

$$
\begin{aligned}
& \text { Controls }
\end{aligned}
$$

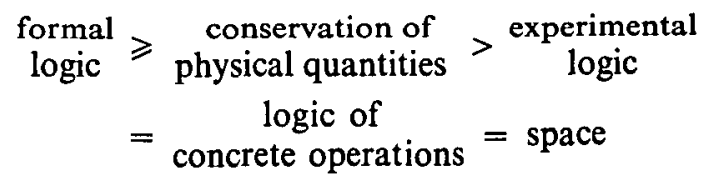

\section{Schizophrenic patients}

$$
\begin{aligned}
& \underset{\text { physical quantities }}{\text { conservation of }}>\begin{array}{l}
\text { formal } \\
\text { logic }
\end{array}> \\
& \begin{array}{c}
\text { logic of concrete } \\
\text { operations }
\end{array}>\text { space }>\begin{array}{l}
\text { experimental } \\
\text { logic. }
\end{array}
\end{aligned}
$$

\section{Qualitative aspects}

The cognitive behaviour of schizophrenic patients in Piaget's genetic tests displayed obvious functional characteristics resulting from the disequilibrium between assimilation and accommodation in their reasoning.

\section{(1) Special features resulting from assimilatory predominance}

The subject is incapable of dissociating himself from his thought processes and assimilates the real or assumed properties of external objects to them in an exaggerated or arbitrary manner. This process can result in a deformation of observable data and false interpretation of experimental data. For example, in tests of logico-experimental reasoning, the subject perceives the water level as descending in a glass in which a piece of sugar is dissolving. When 2 cylinders of equal volume but differing weight are placed in glasses containing water, the subject predicts that the heavier cylinder will cause the water level to rise more and then sees this happen. In the mediate transmission of movement the subject feels the coin which transmits the movement under his fingers 
and sees it move, although in fact it remains stationary. He arbitrarily assimilates previous observations and deductions to inferences with his reasoning, which leads him to distort the former. He also utilizes irrelevant referents, which results in inappropriate analogies and incorrect causal relations.

\section{(2) Special features resulting from accommodatory predominance}

The subject is incapable of dissociating himself from observable data, which leads him to distort the inferences of his reasoning. Thus, in the test of successive classification (trichotomy) of geometric figures as a function of shape, size and colour, the subject begins the test correctly but then becomes side-tracked by one of the object's characteristics and ignores the prescribed classicatory criterion. When a lump of sugar dissolves in water, the observable 'disappearance of sugar' becomes so compelling that it alters the inferences which underly the conservation of physical quantity: the lump of sugar is not conserved, it vanishes in the same way that it disappears physically. The subject may then make a strange casuistical attempt to resolve the contradiction by stating that, although the sugar has disappeared, the water still tastes sugary. In tests of spatial representation, the configuration is so compelling that it prevents the operations from taking place, including the mobilization of the image even though this has already been defined and presented.

(3) Special features which initially seem unrelated to an assimilation/accommodation disequilibrium

These features are characterized by difficulty in (a) relativizing the variables or concepts which underly the reasoning and which are, therefore, treated as absolutes; $(b)$ imagining that any operation can be annulled by the opposite operation; (c) repeating from memory or even imitating an operation which has just been correctly applied to reality; $(d)$ generalizing an idea or an operation to a new problem that is similar to the preceding problem; $(e)$ believing in the validity or reproductibility of a deductive syllogism as if rational evidence were nonexistent.

The total number of these special functional features and their distribution among the various tests were quite different in the 3 populations studied. The controls presented few special features, and almost all of these were in the assimilatory predominance category. The hebephrenic and paranoid schizophrenics presented many more special features. However, the hebephrenics displayed type 2 features (accommodatory predominance) as frequently as type 1 (assimilatory predominance). In contrast, the paranoid schizophrenics presented mostly type 1 (assimilatory predominance) and type 3 features (see Table 1).

\section{DISCUSSION AND CONCLUSIONS}

\section{Cognitive activities in the hebephrenic patient}

The intelligence quotient of the patients (WAIS) was within the normal range, although slightly lower than that of the controls. The structure of their reasoning (Piaget operations) was not impaired. These results support the attempts that clinicians have made for the last 50 years to distinguish the nosological entity of hebephrenia from that of the other forms of schizophrenia. The hebephrenic has difficulty in actualizing his reasoning, and this difficulty varies with the type of operation. Except for the conservation of physical quantities, the patients find the greatest difficulty in the area of logico-experimental reasoning. Can one justifiably consider that this confirms our original hypothesis? A disequilibrium between accommodation and assimilation implies that deductive logico-mathematical operations would be better conserved than logicoexperimental operations, the latter requiring the assimilation of real objects to reasoning and the attribution of operations to these objects. In this perspective, the correct performance of operations which underlie the invariance of physical quantity may seem contradictory. However, in the tests related to changes in appearance of plasticine are the invariants of matter, weight and volume not, in fact, dependent on operations which are virtually deductive? For the adult, at any rate, the physical presence of balls of plasticine is only needed to illustrate a situation. Does not the conservation of weight when the ball is kneaded into the shape of a sausage result from a purely deductive process with only logicomathematical reasoning being invoked? Observable data are virtually irrelevant. The operations 
of compensation and reversibility are immediately generalized and refer to any object whatsoever, in almost the same way as the axiom which states that two quantities equal to a third are equal to each other. This is proved by the fact that with tests involving the dissolving of sugar or weightvolume dissociation the patients obtained wholly different results, similar to those which they obtained with tests of physical causality.

The better performance in some tests of formal logic than in tests involving logic of concrete operations is also highly suggestive. Performance is better conserved in tests of formal logic that are acquired late in childhood (quantification of probabilities, at 12 years) than in tests dependent on the logic of concrete operations; this is especially true of one of the simplest, classification, which is acquired between 8 and 9 years. In the quantification of the probabilities test, the nature and properties of the objects are unimportant. In contrast, in order to classify geometric forms or numbers, it is necessary to abstract a common property from external reality. It is essential that the classificatory schemata assimilate different real objects by means of one of their common characteristics.

It may thus be concluded that hebephrenic reasoning is characterized by a disequilibrium between assimilation and accommodation. The disequilibrium, as demonstrated by the distribution of special functional features in the performance of operations and as shown by clinical observation of the patients during the tests, leads to a constant oscillation between assimilatory and accommodatory predominance.

Complete assimilation of the object to thought, without reciprocal accommodation of the objects, leads to the distortion or to the complete disappearance of the external world. According to Piaget (1959), symbolic play and dreaming are physiological forms of this type of mental functioning. In symbolic play, objects can acquire any meaning and can take on any quality depending on the schemata of action and thought used. The continuity of their functioning depends only on their internal consistency. The latter is only achieved in that other form of symbolic play, mathematical thought. Consistency results from the equilibrium generated by the subject between the reciprocal accommodation and assimilation of schemata of action that the subject has acquired during their coordination.
This equilibrium is both necessary and sufficient as long as the operations deal with objects in the general sense. When, however, they are applied to real objects, the equilibrium between assimilation of the object and accommodation to the object must be constantly re-established and checked.

It is unnecessary to recall the fallacies resulting from conventionalism in the application of thought processes. Schizophrenics reason better when they operate on 'neutral' objects which have no intrinsic meaning and which only acquire meaning via the operations which are performed on them. It is easier for the patients to imagine combinations of pairs of general objects than to perform these combinations using real objects which are inserted into real object holders. In the transition from assimilatory dominance to accommodatory predominance, they fall into discontinuity. When, because of the experimental situation (especially in dealing with spatial configurations), accommodation predominates, the patients are compelled to imitate and are thus prevented from carrying out the operation. For example, when required to draw the shadow of a circle pivoting on its diameter, they draw a circle and simply indicate with a gesture that it should turn. Similarly, when required to draw the plane of section of a volume, they reproduce the volume as they see it, drawing a line to indicate the plane of section. When assimilation is dominant, the reasoning process distorts the observable data to the extent that all experiential verification becomes impossible. In the case of oscillation between assimilatory and accommodatory predominance, the subjects arrive at a series of contradictory solutions which they are unable to reconcile, all of them appearing equally valid.

\section{Speculation}

These results explain certain characteristics of the cognitive activity of hebephrenic schizophrenics which are not dissimilar to the traditional clinical semeiology of this nosological entity. Classical descriptions emphasize the discontinuity and discordance between the thinking and the action of hebephrenics, and their perplexity and ambivalence. Bleuler's neologism, 'autism', refers to the disruption of the equilibrium between the subject and the external world, which is reflected by withdrawal and isolation, sometimes alternating with periods of 
totally imitative behaviour. Clearly these phenomena are more clinically obvious, in the affective behaviour of the patients than in their intellectual activities. But it is highly probable that the assimilation/accommodation equilibrium of affective schemata is as important as that of cognitive schemata, although less well known. In phenomenological terms, autism is experienced as depersonalization and as loss of subject (self) identity, with its corollary of loss of the distinction between subject and object. In complete assimilation, the object is destroyed by being incorporated into a subject which loses all limits. In complete accommodation, the subject dissolves into the object, the latter losing its outlines.

\section{Cognitive activities in paranoid schizophrenia}

Like the hebephrenic patients, the paranoid schizophrenic displayed a normal intelligence quotient (WAIS), although this was lower than that of the controls. Their operational activities were not disorganized. As with the hebephenic patients, a disequilibrium between assimilation and accommodation accounts for their poor performance. Like the hebephrenics, they have more difficulty with logico-experimental reasoning than with logico-mathematical reasoning. The special functioning features of their reasoning, particularly marked in the area of logicoexperimental reasoning, are due essentially to an assimilatory predominance and a resultant deficiency of accommodation.

In addition, paranoid schizophrenics also present deficits in logico-mathematical reasoning. They have more difficulty, for example, in achieving the inclusion of classes (stage IIA, performed by the normal child at age 7) than hebephrenics. They exhibit functional special features in reasoning which, at first glance, appear unrelated to the assimilation/accommodation equilibrium.

In view of the results derived from the paranoid schizophrenics it is worth analysing sequentially the special functional features of their reasoning. These patients have difficulty in generalizing their reasoning to situations which, although different, are isomorphic, or when a new variable is introduced. These specific features are probably due partly simply to the defect in accommodating their reasoning to the specifics of the real world. We are dealing here, at least in part, with what Piaget terms inductive generalization (Piaget et al.
1978), which is related to the empirical abstraction of the properties of the real world. This process occurs before the subject makes any observation whatsoever. An operation which assimilates these properties without any accommodation to them will appear different from the same operation which assimilates, without accommodation, other properties of the external world. An analogy can be drawn with the child's symbolic play or with dreaming, both of these activities being purely assimilatory according to Piaget (1959). Tying together and pulling several different objects with the same string does not allow one to conclude that it is the same action that is involved. Pulling a pebble may mean walking a dog, pulling a locomotive means driving a train, leading a horse means riding in the Far West. Similarly, in dreams, the same instinctive-affective schemata of fear can assimilate several different persons or situations one after the other and give the illusion of wholly different heterogeneous dreams. In sum, these difficulties with the inductive generalization of operations, like other deficits observed in the logico-experimental area of reasoning, are probably related to assimilatory predominance and its corollary, insufficient accommodation of operations during their immediate actualization.

The deficit of generalization which prevents the subject from recognizing, for example, the isomorphism in the test of transitivity of size, in formal problems such as $A>B, B>C, A>C$, or as in Caroline $>$ Betty, Betty $>$ Suzanne, Caroline > Suzanne, has a completely different origin. In this case we are not dealing with inductive generalization but with constructive generalization, involving what Piaget terms reflecting abstractions (Piaget et al. 1977a, $b$, 1978). In tests of class inclusion, we consider the failures and the laboriously achieved successes of the paranoid schizophrenics to have the same cause, a difficulty in delimiting reflecting abstractions. Thus, one of our patients, after agreeing that birds are animals, reasoned in the following way in response to the question: Are there more birds than animals in the world? 'Well, in the whole world, I don't know... I think there are more birds because birds... they are all over, whereas other animals are somewhere... localized.' Birds are animals. 'There are animals in the oceans, there are... infinite numbers of them 
there.' In that case, are there more animals or more birds? 'Birds are animals, they belong to the animal kingdom.' Yes. 'Only we are human, whereas the other species are animals or miniofiric species [sic] or...' The subject was completely unable to formulate any inclusion relation.

Thus, some of our patients experienced the greatest difficulty when presented with the following simple problem: sub-class $A$, included in the general class $B$, is smaller than $B$. However, it is clear that their operational level, as demonstrated by the tests of conservation of physical quantities, should enable them to solve the problem easily and recognize that $A$ is obviously smaller than $B$. What is the cause of this well known surprising difficulty? It is that the concept 'class of birds' is not an empirical abstraction, as common sense would imply it to be. More precisely, even if the concept of birds is an empirical abstraction based on some of their essential characteristics (flying, possessing 2 feet, etc.), it only forms an intensive class, delimited in terms of comprehension but not in terms of extension. The concept of an extensive class presupposes the existence of a reflecting abstraction. In other words, as Piaget points out (Piaget et al. 1978), it not only requires the assimilation of new content to pre-existing forms (analogy), but new forms and new contents must be generated by the reciprocal assimilation of schemata which are initially conceived as heterogeneous. In the case under discussion, generating the concept of the extensive class of birds is not tantamount merely to using empirical abstraction so as to extract from reality some specific properties of birds. Rather, it means integrating the classification schema of 'birds' with the classification schema of 'non-birds'. As Piaget observes (Piaget et al. 1978), 'the most important condition for the regulation of extensions and the determination of inclusion is that what had been perceived to be simple "differences" between the positive qualities of the objects being comprehended should be elevated to the rank of negation, compensating accurately for the positive characteristics of the objects and classes'. It seems evident to us that the transition from the opposition of positive classes defined in terms of comprehension ('birds'/'dogs'/'fish') to the opposition to the class of 'birds' delimited in terms of extension to the class delimited in terms of extension at the same level ('non-birds') is linked to compensation of the affirmations by the negations. This transition results from the reciprocal integration of intensive classification schemata through the maintenance of a strict equilibrium between assimilation and accommodation. To conceive that to each positive class $A$ there is a corresponding reciprocal negative class non- $A$ is the result of the reflecting abstraction of accommodation to the rest of the classification schemata of assimilatory activity of the ensemble of $A \mathrm{~s}$. If such is the case, one can understand why the paranoid schizophrenics, being inveterate assimilators, fail to understand (or do so only with great difficulty, independent of their operational level) that the general class of $B$ is composed of $A$ and non- $A$ and that, therefore, the $A$ s are evidently fewer in number than the $B$ s.

It is not surprising that they are unable to grasp the isomorphism of a problem such as the transitivity of sizes, whether it is presented formally as $A>B>C, A>C$, or in the concrete form of circles of increasing diameter, or as individuals of increasing height. The reflecting abstraction of the positive concept 'greater than' implies its negative corollary 'smaller than', and requires that all the other positive properties of the objects or symbols under discussion be ignored. The problem appears to be fleeting to the subject when expressed formally. The result is that if Caroline is taller than Betty and Betty is taller than Suzanne, it is necessary to measure them (empirical abstraction) in order to be sure that Caroline is taller than Suzanne.

Therefore, logico-mathematical reasoning no longer generates any evidence and we are not surprised to discover that the paranoid schizophrenic is unable to affirm that 2 quantities equal to a third are equal to each other in any circumstances and at all times. When confronted with any deductive affirmation the patient finds himself in the situation that we experience when faced with the illogical syllogism: Socrates is mortal, Socrates is a man, therefore men are mortal. The conclusion may be true but the proof is not convincing.

According to our original hypothesis, the disequilibrium between assimilation and accommodation is displayed in schizophrenics only in the here and now actualization of their operations. The performance of the paranoid schizophrenics leads us, however, to admit that this 
disequilibrium also has an impact, although to a lesser extent, on the reciprocal assimilation and accommodation of the schemata and operations which are at the base of logico-mathematical reasoning and its productivity.

In the paranoid schizophrenic the assimilation of the delusions to the reasoning, not counterbalanced by accommodation, is thus not the only explanation for the unshakeable nature of the convictions. This would appear to be compounded by an inability to achieve certainty by logico-mathematical and logico-experimental reasoning, thus clearly leaving the way open for convictions based on magical reasoning. Thus, on top of the assimilatory predominance in his immediate personal experiences, the mechanism described by Bergson (1945) would seem to come into play to support the patient's delusions: when rational explanations and the certainty they produce are lacking, magical causality and subjective certainty take their place.

\section{REFERENCES}

Bergson, H. (1945). Les deux sources de la morale et de la religion. Skira Ed.: Geneva.

Burnand, Y., Zutter, A.-M., Burgermeister, J. J. \& Tissot, R. (1980). Quelques aspects des activités cognitives du schizophrène. L'Encéphale (in the press).

Piaget, J. (1950). Introduction d l'épistémologie génétique (3 vols.). PUF: Paris.
Piaget, J. (1959). La formation du symbole chez l'enfant. Delachaux \& Niestlé: Paris.

Piaget, J. \& Inhelder, B. (1941). Le développement des quantités physiques chez l'enfant. Delachaux \& Niestlé: Neuchâtel.

Piaget, J. \& Inhelder, B. (1948). La représentation de l'espace chez l'enfant. PUF: Paris.

Piaget, J. \& Inhelder, B. (1951). La genèse de l'idée de hasard chez l'enfant. PUF: Paris.

Piaget, J. \& Inhelder, B. (1959). La genèse des structures logiques élémentaires. Delachaux \& Niestlé: Neuchâtel.

Piaget, J. \& Inhelder, B. (1966). L'image mentale chez l'enfant. PUF: Paris.

Piaget, J. et al. (1972). La transmission des mouvements, pp. 4797. Etudes d'épistémologie génétique no.27. PUF: Paris.

Piaget, J. et al. (1974a). Recherches sur la contradiction. Volume 1: Les différentes formes de la contradiction. Etudes d'épistémologie génétique no. 31. PUF: Paris.

Piaget, J. et al. (1974b). Recherches sur la contradiction. Volume 2: Les relations entre affimations et négations. Etudes d'épistémologie génétique no. 32. PUF: Paris.

Piaget, J. et al. (1977a). Recherches sur l'abstraction réféchissante. Volume 1: L'abstraction des relations logicoarithmétiques. Etudes d'épistémologie génétique no. 34. PUF: Paris.

Piaget, J. et al. (1977b). Recherches sur l'abstraction réfléchissante. Volume 2: L'abstraction de lordre des relations spatiales. Etudes d'épistémologie génétique no. 35. PUF: Paris.

Piaget, J. et al. (1978). Recherches sur la généralisation. Etudes d'épistémologie génétique no. 36. PUF: Paris.

Schmid-Kitsikis, E., Zutter, A.-M., Burnand, Y., Burgermeister, J. J., Tissot, R. \& Ajuriaguerra, J. de (1975). Quelques aspects des activités cognitives du schizophrène. Annales médico-psychologiques (Paris) 133 (2), 197-236.

Tissot, R. (1979). Introduction à la psychiatrie biologique. Masson: Paris. 